\title{
COMMENTARY
}

\section{Tissue saturation measurement - exciting prospects, but standardisation and reference data still needed}

\author{
Nicola Jones' and Marius Terblanche, ${ }^{1,2 *}$ \\ See related research by Možina and Podbregar, http://ccforum.com/content/14/2/R42
}

\begin{abstract}
Sepsis and shock result in disturbances in microcirculatory perfusion and tissue oxygen utilisation that may not be reflected in global measures of haemodynamics. Near-infrared spectroscopy enables measurement of tissue oxygen saturation $\left(\mathrm{StO}_{2}\right)$ and provides information on local microvascular and mitochondrial function. This measure could be incorporated with existing targets of goal-directed therapy to provide an integrated approach to haemodynamic resuscitation of both the macro- and microcirculation in various shock states. However, key methodological factors must be addressed before widespread clinical application.
\end{abstract}

In the previous issue of Critical Care, Možina and Podbregar report that changes in thenar muscle tissue saturation $\left(\mathrm{StO}_{2}\right)$ in response to vascular occlusion can be used to predict discrepancy between central $\left(\mathrm{ScvO}_{2}\right)$ and mixed $\left(\mathrm{SvO}_{2}\right)$ venous oxygen saturation in patients with combined severe left ventricular failure and sepsis [1].

On first read this study is conceptually difficult. Essentially, $\mathrm{ScvO}_{2}$ is a surrogate marker of $\mathrm{SvO}_{2}$ and is widely used to assess adequacy of oxygen delivery, and to guide the initial resuscitation of septic patients [2]. Trends in $\mathrm{ScvO}_{2}$ may reflect those in $\mathrm{SvO}_{2}$, but alterations in oxygen extraction and redistribution of blood flow away from peripheral and splanchnic circulations in various shock states may cause clinically important differences between these values [3]. In these circumstances $\mathrm{ScvO}_{2}$ may be maintained despite abnormally low

*Correspondence: marius.terblanche@kcl.ac.uk

'Department of Critical Care Medicine, Guy's and St Thomas' NHS Foundation Trust, London SE1 7EH, UK

Full list of author information is available at the end of the article
$\mathrm{SvO}_{2}$ and significant tissue hypoxia. The current study suggests a means to identify these discrepancies which may be useful in the management of sepsis/septic shock, particularly in patients with complex haemodynamic disturbances. However, several issues relating to methodological factors require further consideration.

Microcirculatory perfusion and tissue oxygen utilization are affected by sepsis and shock [4]. These derangements can be studied non-invasively using near-infrared spectroscopy, a technique that is able to determine the oxygenation status of tissue haemoglobin. Decreased $\mathrm{StO}_{2}$ reflects the presence of severe hypoperfusion and has been used clinically to guide resuscitation during hypovolaemic shock [5]. Unfortunately, in sepsis/septic shock absolute values of $\mathrm{StO}_{2}$ do not reliably differentiate patients from healthy individuals [6].

The discriminatory power and predictive ability of $\mathrm{StO}_{2}$ can, however, be improved by measuring the response to an ischaemic challenge. The vascular occlusion test (VOT) is a provocative test in which $\mathrm{StO}_{2}$ is measured at a peripheral site (such as the thenar eminence) whilst a transient rapid vascular occlusion is performed for either a defined time interval or until a pre-defined $\mathrm{StO}_{2}$ value is reached. The VOT-derived $\mathrm{StO}_{2}$ trace can be divided into four phases - baseline, ischemia, reperfusion, and hyperemia - and parameters can be measured for each of these. These include: rate of deoxygenation $\left(\mathrm{DeO}_{2}\right)$, measured from the $\mathrm{StO}_{2}$ downslope during the ischaemic phase - this is generally considered to reflect local muscle metabolism and mitochondrial oxygen consumption [7]; and rate of reoxygenation $\left(\mathrm{ReO}_{2}\right)$, measured from the $\mathrm{StO}_{2}$ upslope during reperfusion - this is the time required to wash out stagnant blood and is thought to reflect the reactivity of the microcirculation [8].

Studies suggest that the response to the VOT differs in sepsis, with a slower $\mathrm{DeO}_{2}$ during cuff occlusion and a prolonged $\mathrm{ReO}_{2}$ during reperfusion when compared to healthy individuals $[9,10]$. Furthermore, it seems that VOT reflects severity of illness and is sensitive to intervention with activated protein $C[8,11]$. According 
to the current study it may also have a role in guiding resuscitation and optimisation of haemodynamics.

These findings are exciting, but at present enthusiasm must be tempered. Firstly, there are wide variations in $\mathrm{StO}_{2}$ and VOT-derived parameters dependent upon probe position and probe size [12]. Secondly, the VOT procedure has yet to be standardized; currently, different types and degrees of deflation thresholds (for example, absolute $\mathrm{StO}_{2}$ of $40 \%$ or $50 \%$ versus duration of 3 minutes, 4 minutes, 5 minutes) are employed [13]. Thirdly, context-specific ranges for VOT-derived $\mathrm{StO}_{2}$ parameters need to be established in health to ensure correct interpretation of responses in pathological states. High quality data are also needed on the VOT parameter values for different levels of disease severity, and indeed for different diseases. Finally, the mechanisms underlying differences in $\mathrm{StO}_{2}$ response observed in sepsis need to be fully characterized.

Dynamic $\mathrm{StO}_{2}$ monitoring is a promising technique with the potential to provide a non-invasive 'biopsy' of microvascular and mitochondrial function. Used in conjunction with global measures of oxygen delivery it could provide an integrated approach to haemodynamic resuscitation of both the macro- and microcirculation in various shock states. Furthermore, it may have utility in determining disease severity, outcome prediction, assessment of the biological effects of interventions, and in guiding future research. However, as with all new technologies it is essential that operating characteristics are robustly defined and that the limitations are fully appreciated before wider application to the clinical setting.

\section{Abbreviations}

$\mathrm{DeO}_{2}=$ rate of deoxygenation; $\mathrm{ReO}_{2}=$ rate of reoxygenation; $\mathrm{ScvO}_{2}=$ central venous oxygen saturation; $\mathrm{StO}_{2}=$ tissue oxygen saturation; $\mathrm{SvO}_{2}=$ mixed venous oxygen saturation; $\mathrm{VOT}^{2}=$ vascular occlusion test.

\section{Competing interests}

MT has received $\mathrm{StO}_{2}$ equipment in support of research from Hutchinson Technology Inc.

\section{Author details}

'Department of Critical Care Medicine, Guy's and St Thomas' NHS Foundation Trust, London SE1 7EH, UK. ${ }^{2}$ Critical Care Research Group, King's Health Partners Academic Health Sciences Centre, London SE1 7EH, UK.
Published: 24 June 2010

\section{References}

1. Možina H, Podbregar M: Near-infrared spectroscopy during stagnant ischemia estimates central venous oxygen saturation and mixed venous oxygen saturation discrepancy in patients with severe left heart failure and additional sepsis/septic shock. Crit Care 2010, 14:R42.

2. Rivers E, Nguyen B, Havstad S, Ressler J, Muzzin A, Knoblich B, Peterson E, Tomlanovich M: Early goal-directed therapy in the treatment of severe sepsis and septic shock. N Eng/ J Med 2001, 345:1368-1377.

3. Varpula M, Karlsson S, Ruokonen E, Pettila V: Mixed venous oxygen saturation cannot be estimated by central venous oxygen saturation in septic shock. Intensive Care Med 2006, 32:1336-1343.

4. Spronk PE, Zandstra DF, Ince C: Bench-to-bedside review: sepsis is a disease of the microcirculation. Crit Care 2004, 8:462-468.

5. McKinley BA, Marvin RG, Cocanour CS, Moore FA: Tissue hemoglobin $\mathrm{O} 2$ saturation during resuscitation of traumatic shock monitored using near infrared spectrometry. J Trauma 2000, 48:637-642.

6. De Blasi RA: Is muscle StO2 an appropriate variable for investigating early compensatory tissue mechanisms under physiological and pathological conditions? Intensive Care Med 2008, 34:1557-1559.

7. Gomez H, Torres A, Polanco P, Kim HK, Zenker S, Puyana JC, Pinsky MR: Use of non-invasive NIRS during a vascular occlusion test to assess dynamic tissue O(2) saturation response. Intensive Care Med 2008, 34:1600-1607.

8. Creteur J, Carollo T, Soldati G, Buchele G, De Backer D, Vincent JL: The prognostic value of muscle StO2 in septic patients. Intensive Care Med 2007, 33:1549-1556

9. Pareznik R, Knezevic R, Voga G, Podbregar M: Changes in muscle tissue oxygenation during stagnant ischemia in septic patients. Intensive Care Med 2006, 32:87-92.

10. Payen D, Luengo C, Heyer L, Resche-Rigon M, Kerever S, Damoisel C, Losser MR: Is thenar tissue hemoglobin oxygen saturation in septic shock related to macrohemodynamic variables and outcome? Crit Care 2009, 13 Suppl 5:S6.

11. Donati A, Romanelli M, Botticelli L, Valentini A, Gabbanelli V, Nataloni S, Principi T, Pelaia P, Bezemer R, Ince C: Recombinant activated protein C treatment improves tissue perfusion and oxygenation in septic patients measured by near-infrared spectroscopy. Crit Care 2009, 13 Suppl 5:S12.

12. Bezemer R, Lima A, Myers D, Klijn E, Heger M, Goedhart PT, Bakker J, Ince C: Assessment of tissue oxygen saturation during a vascular occlusion test using near-infrared spectroscopy: the role of probe spacing and measurement site studied in healthy volunteers. Crit Care 2009, 13 Suppl 5:S4.

13. Gomez H, Mesquida J, Simon P, Kim HK, Puyana JC, Ince C, Pinsky MR: Characterization of tissue oxygen saturation and the vascular occlusion test: influence of measurement sites, probe sizes and deflation thresholds. Crit Care 2009, 13 Suppl 5:S3.

doi:10.1186/cc8970

Cite this article as: Jones N, Terblanche M: Tissue saturation measurement exciting prospects, but standardisation and reference data still needed. Critical Care 2010, 14:169. 